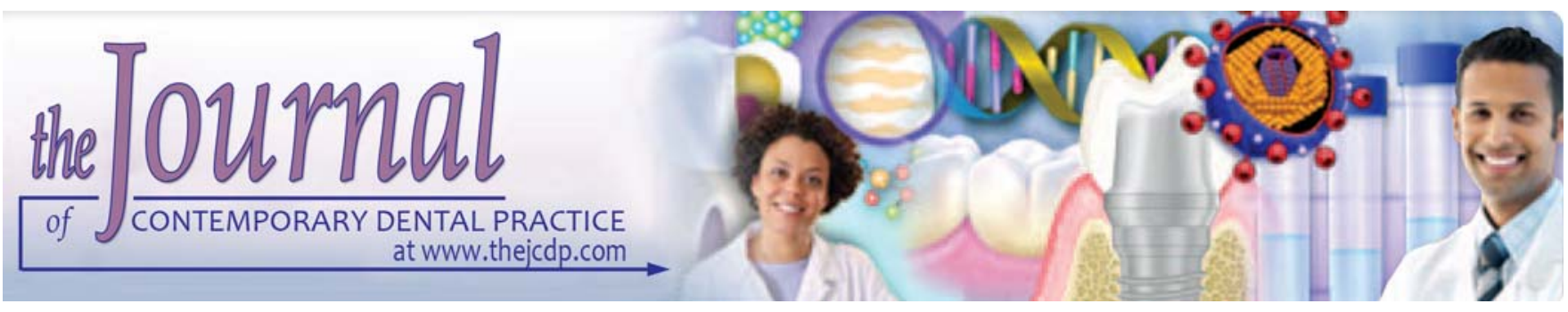

\title{
Shade Matching Performance of Dental Students with Three Various Lighting Conditions
}

\author{
Mohammadreza Nakhaei, Jalil Ghanbarzadeh, Shirin Keyvanloo, Samin Alavi, Hamid Jafarzadeh
}

\section{ABSTRACT}

Aim: To evaluate the ability of dental students to match shades under three various light conditions.

\begin{abstract}
Materials and methods: Sixty senior dental students participated in this study. All students were tested for color deficiency using Ishahara's tests. Nine classical vita shade tabs were randomly selected and their identification codes were concealed. The students were asked to match these 9 selected items by using a complete vita shade guide under three various light conditions (natural light, clinical light, and correcting light source). The chosen shade tabs were recorded and the correct matches were counted. Scores were calculated by adding the number of correct matches.
\end{abstract}

Results: The mean values of correct match scores with natural light, clinical light and correcting light source were 4.82, 4.75 and 6.82 , respectively. There was no significant difference in correct matches scores between men and women, nor among various vita $A, B, C$ and $D$ shades.

Conclusion: The students showed a better performance in shade matching under the correcting light source than natural light and clinical light. Gender had no effect on shade matching selection and there was no difference in shade matching ability among vita $A, B, C, D$ shades.

Clinical significance: Shade matching performance is significantly improved with correcting light source.

Keywords: Shade matching, Lightsource, Shade guide, Dental student.

How to cite this article: Nakhaei M, Ghanbarzadeh J , Keyvanloo S, Alavi S, J afarzadeh $\mathrm{H}$. Shade Matching Performance of Dental Students with Three Various Lighting Conditions. J Contemp Dent Pract 2013;14(1):100-103.

\section{Source of support: Nil}

Conflict of interest: None declared

\section{INTRODUCTION}

Shade matching performance of dentists and transmitting it to the laboratory is an essential factor in natural tooth color reproduction. There are various methods to select shades, including the use of colorimeter, spectrophotometer, computer software and digital photos; their efficacy has been proved..$^{1-3} \mathrm{~A}$ lthough the shade-matching devices may hel $p$ the clinicians, but they cannot solve all the problems involved in shade taking procedure. ${ }^{4}$ Consequently the shade-matching procedure is commonly performed by clinician through comparison remaining tooth shades with a commercially available shade guide.

Shade matching ability is influenced by various factors. It varies due to age, experience and the degree of individual color deficiency. A ging leads to yellowing lens and cornea of human eyes which results in a tendency toward seeing objects in yellow and brown. ${ }^{5}$ Color vision deficiency is an inherited and $\mathrm{X}$-linked disorder which affecting men more than women. Color defect can be diagnosed by using Ishahara's tests, an instrument that provides accurate and quick differentiation.

Professional experience is an effective factor in shade matching so that dental care practitioners who routinely perform restorative procedure show a high ability in shade matching. ${ }^{6-8}$ Furthermore, visual shade matching is an acquired skill which progressively improves through clinical experiences. ${ }^{9}$ However, in some studies experience is not proved to be an influential factor. ${ }^{10-12}$

The type of lighting is a critical component that affects shade selection and external light conditions obviously have significant effect on shade matching in dentistry. ${ }^{10,13-17}$ The ideal lighting condition for this procedure is the natural light which occurs between midday and 3 PM or North sky daylight but this condition varies with the time of day, cloud cover, humidity and pollution. ${ }^{13,18}$ Therefore, the use of daylight lamps has been recommended to standardize light conditions and improve the ability of color matching. ${ }^{13,16}$

However, most of the clinicians perform the process of color matching in the clinic under the clinical light condition or in natural daylight. The purpose of this study is to compare 
shade matching performance under the three light sources including natural light, clinical light and correcting light source.

\section{MATERIALS AND METHODS}

Sixty dental students including 30 male and 30 female participated in this study. All students performed Ishahar's tests to determine color deficiency. In order to eliminate possible bias caused due to color vision defect, participants involved with color vision deficiency were excluded from study. A n optometrist was invited to test the students. For tooth matching procedure, two shade guides were used.

From the first shade guide, 9 shade tabs including $C 2$, C3, B 3, B2, B 1, A 3, A 2 and D2 were randomly selected. The identification codes of 9 shade tabs were concealed and the students were asked to match the shade tabs with concealed code by using complete shade guide. Ten minutes were allocated for this procedure. Time was limited because allowing more time increases error possibility. The students matched the shades under the correcting light, natural light and clinical lighting condition. The clinical lighting condition was a compound of natural light and fluorescent light as well as incandescent. Shade matching under the correcting light was performed in a room which had been allocated for this procedure. In order to reduce eye fatigue, the walls were painted gray and 2 day light lamps (Germany, Osram Biolux, L 36w/965, CR > 90) were installed.

For shade matching, the students stand under this light source so that no shade was cast over shade matching guides. Shade matching under natural light was conducted during the late spring between the hours of $9 \mathrm{AM}$ and $3 \mathrm{PM}$. As previous subjective background can adversely affect shade matching, there was an interval of 1 week between sessions of shade selection. A special questionnaire was allotted to each student. Having completed the matching of selected items (shade tabs with the identification code concealed) to a vita shade guide, the chosen shade tabs were recorded and the correct matches were counted. Scores were calculated by adding the number of correct matches. The highest score was be considered, if a student matched all the items successfully.

The data were statistically analyzed using MannWhiteny test and one-way A NOV A test.

\section{RESULTS}

In this study, 60 senior dental students participated. The percentage of correct and incorrect matches for each item were calculated and ranged from the lowest to the highest (Table 1). K ruskal-W allis test revealed significant differences in shade matching under the three light sources ( $p>0 / 001$ ) (Table 2). The number of correct choices under the correcting light source was significantly higher than two other light sources $(p<0.001)$ but there was no significant difference between natural light and clinical light $(p=0.817)$ (Table 2).

$M$ ann-W hiteny test found no differences between male and female students in correct match scores under three light sources (Table 3).

Table 4 shows mean percent of correct matches for various hues under three light sources. One-way A N OV A revealed no differences in the mean percent of correct matches among the various $A, B, C$ and $D$ hues $(p=0.924)$.

\section{DISCUSSION}

The light source is an effective factor in shade matching. Although natural light has been suggested to be the ideal light source for matching shades, the quality of day light is not consistent and it is not al ways possible to choose shades during the day. Therefore, using a consistent light source and an appropriate environmental condition will improve the shade matching performance. This study showed that shade-matching ability of dental students were better under correcting light than those under natural light or clinical light conditions.

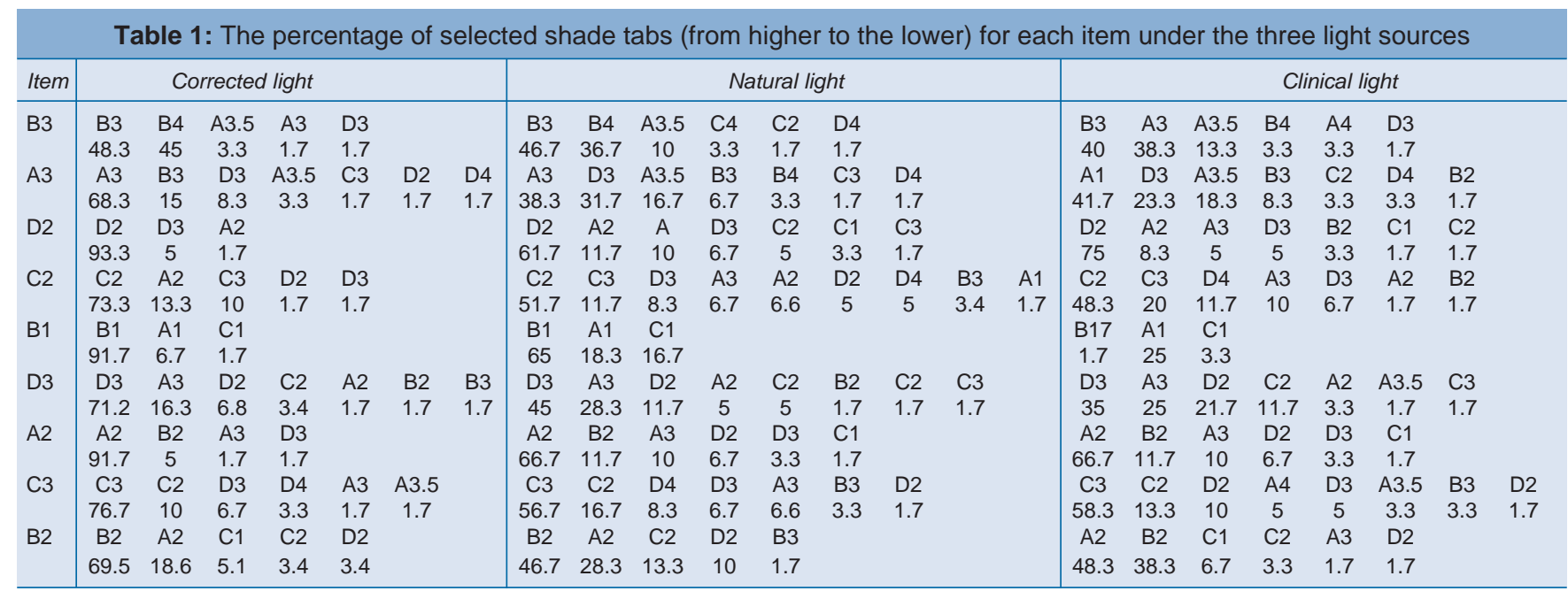


Table 2: Mean correct shade match scores of dental students by three light sources

\begin{tabular}{lcc}
\hline Light source & $M D \pm S D$ & Mann-Whitney test \\
\hline (A) Corrected light & $6.82 \pm 1.39$ & $\mathrm{~A}: \mathrm{B}, \mathrm{p}<0.001$ \\
(B) Clinical condition & $4.75 \pm 1.65$ & $\mathrm{~B}: \mathrm{C}, \mathrm{p}=0.817$ \\
(C) Natural light & $4.82 \pm 1.87$ & $\mathrm{C}: \mathrm{A}, \mathrm{p}<0.001$
\end{tabular}

Kruskal-Wallis test, $p<0.001$

\begin{tabular}{|c|c|c|c|}
\hline \multirow[t]{2}{*}{ Light source } & \multicolumn{2}{|c|}{$\begin{array}{l}\text { Mean values of correct } \\
\text { match scores }\end{array}$} & \multirow[t]{2}{*}{$\begin{array}{c}\text { Mann-Whitney } \\
\text { test }\end{array}$} \\
\hline & $\begin{array}{c}\text { Male } \\
(n=30)\end{array}$ & $\begin{array}{l}\text { Female } \\
(n=30)\end{array}$ & \\
\hline Corrected light & $6.7 \pm 1.31$ & $6.93 \pm 1.48$ & 0.324 \\
\hline Clinical condition & $4.57 \pm 1.59$ & $4.93 \pm 1.72$ & 0.405 \\
\hline Natural light & $4.77 \pm 1.75$ & $4.82 \pm 2.01$ & 0.840 \\
\hline
\end{tabular}

Kruskal-Wallis test, $p<0.001$

\begin{tabular}{|c|c|c|c|}
\hline Shade tab & Corrected light & Clinical light & Natural light \\
\hline A Vita shade & 80 & 54.2 & 52.5 \\
\hline B Vita shade & 69.8 & 50 & 52.5 \\
\hline C Vita shade & 75 & 53.3 & 54.2 \\
\hline D Vita shade & 82.25 & 55 & 52.3 \\
\hline
\end{tabular}

ANOVA, $p=0.924$

In this study the senior students were asked to participate so as to minimize the variability of different factors such as age, degree of knowledge, training and experience. In order to reduce eye fatigue and approach the standard condition of shade matching, this procedure was performed under correcting daylight lamp in an allocated room. 19, 20 This ideal light condition was compared with the condition in which most clinicians perform shade matching.

Classical vita shade guide chose for this study because it is commonly used by dentists. However, the major limitation of classical vita shade guide is that the numerical values do not reflect regular distribution in value and chroma. Clinicians with less experience demonstrated more success in shade selection with vita 3D - M aster, a systematic designed shade guide. It is a fact that the number of correct matches might increase if the vita 3D-M aster shade guides had been used instead. ${ }^{7,21-23}$

Similar to the result of the other studies, the students had more problems for matching correct hue so that when an incorrect tab was chosen, it had the same value or chroma as the correct shade tab, but was a different hue. ${ }^{10,11} \mathrm{~F}$ or example, the incorrect choice for shade tab B 1 was A 1 and for D2 was A 2.

This finding is also in agreement with other clinical observations which indicated that human eyes are more sensitive to value than to hue and chroma. ${ }^{24}$ Certainly this result is obtained with regard to comparison of numerical values of shade tabs. Further studies are required to evaluate of the target shade tab and incorrect choice by spectrophotometer and calculation of color difference (D elta E) and (Delta L, Delta a, Delta b) color distribution between them.

The results supported other studies that the external light condition is one of the most effective factors on shade matching performance and the correcting light source improves shade selection. ${ }^{10,11,13,16,23}$ A Iso, it has been reported lighting condition can effect on shade matching ability of color vision deficient subjects and there is a notable improvement in their shade matching performance with low temperature illuminant. ${ }^{25,26}$

There were no significant differences in shade matching ability based on gender. This lack of difference was predictable and consistent with other studies. $6,10,11,27$ However, in one study, females achieved significantly better shade matching result than males. ${ }^{12}$

As the most of the students reported, shade matching procedure under daylight lamp and in the allocated room under controlled lighting condition was more convenient than under other conditions. However, as visual shade matching is a subjective phenomenon, no objective evidence is possible to present. There were no significant differences among mean percent correct matches for various hues (A, $B, C, D$ vita) under three light sources. However, in two similar studies, it has been reported that vita $\mathrm{C}$ shade was least likely to be matched. The discrepancy in the different studies results could be due to differences in the method of them. In two aforementioned studies, participants matched the shades of concealed codes tabs by using five choices shade tabs whereas in the present study complete vita shade guide was used.

A limitation of this study was that only shade tab matching has been investigated while more studies are necessary on matching shade tabs with natural teeth and evaluation by shade measurement device. Within the limitation of this study, using standard light source with full spectrum and providing and appropriate conditions in the clinic is recommended. Nowadays, artificial lights are used commonly in the most of the dental clinics and also lots of dental practices are performed when standard daylight is rarely available. The following condition can adversely affect the shade matching procedure; consequently it is necessary to allocate a special place for shade selection.

\section{CONCLUSION}

In this study where the students matched a shade tab with another the ability of shade matching under the corrective 
light source was better than those performed under natural light and clinical light sources. Gender did not have any effect on in shade matching procedure and there was no significant difference among vita A, B, C, D shade in shade matching ability.

\section{CLINICAL SIGNIFICANCE}

Shade matching performance is significantly improved with correcting light source.

\section{REFERENCES}

1. Browning WD, Chan DC, Blalock J S, Brackett M G. A comparison of human raters and an intraoral spectrophotometer. Oper Dent 2009;34(3):337-43.

2. Kim-Pusateri S, B rewer JD, Dunford RG, Wee AG. In vitro model to evaluate reliability and accuracy of a dental shadematching instrument. J Prosthet Dent 2007;98(5):353-58.

3. Schropp L. Shade matching assisted by digital photography and computer software. J Prosthodont 2009;18(3):235-41.

4. Judeh A, AI-W ahadni A. A comparison between conventional visual and spectrophotometric methods for shade selection. Quintessence Int 2009;40(9):e69-79.

5. N guyen-Tri D, Overbury 0, Faubert J. The role of Ienticular senescence in age-related color vision changes. Invest Ophthalmol V is Sci 2003;44(8):3698-704.

6. Capa N, M alkondu O, K azazoglu E, Cal ikkocaoglu S. Evaluating factors that affect the shade-matching ability of dentists, dental staff members and laypeople. J Am Dent Assoc 2010;141(1): 71-76.

7. Hammad IA. Intrarater repeatability of shade selections with two shade guides. J Prosthet Dent 2003;89(1):50-53.

8. Della Bona A, Barrett A A, Rosa V, Pinzetta C. Visual and instrumental agreement in dental shade selection: Three distinct observer populations and shade matching protocols. D ent $M$ ater 2009;25(2):276-81.

9. Jaju RA, N agai S, K arimbux N, Da Silva JD. Evaluating tooth color matching ability of dental students. J Dent Educ 2010; 74(9):1002-10.

10. Curd FM, Jasinevicius TR, Graves A, Cox V, Sadan A. Comparison of the shade matching ability of dental students using two light sources. J Prosthet Dent 2006;96(6):391-96.

11. Jasinevicius TR, Curd FM, Schilling L, Sadan A. Shadematching abilities of dental laboratory technicians using a commercial light source. J Prosthodont 2009;18(1):60-63.

12. Haddad HJ , JakstatHA, A rnetzl G, B orbely J, V ichi A, D umfahrt $H$, et al. D oes gender and experience influence shade matching quality? J Dent 2009; 37 (Suppl) 1:e40-44.

13. Dagg H, O'Connell B, Claffey N, Byrne D, Gorman C. The influence of some different factors on the accuracy of shade selection. J Oral Rehabil 2004;31(9):900-04.

14. Brewer JD, W ee A, Seghi R. A dvances in color matching. D ent Clin North A m 2004;48(2):341-58.

15. Fondriest J. Shade matching in restorative dentistry: The science and strategies. Int J Periodontics Restorative Dent 2003; 23(5):467-79.

16. Corcodel N, Rammelsberg P, M oldovan O, D reyhaupt J, Hassel A J . Effect of external light conditions during matching of tooth color: An intraindividual comparison. Int J Prosthodont 2009; 22(1):75-77.
17. Park JH, LeeYK, Lim BS. Influence of illuminants on the color distribution of shade guides. J Prosthet Dent 2006;96(6):402-11.

18. Rosentiel F, Land MF, Fujimoto J. Contemporary Fixed Prosthodontics. St. Louis: M osby 2006;709-39.

19. Barna GJ , Taylor JW , K ing GE, Pelleu G B J r. The influence of selected light intensities on color perception within the color range of natural teeth. J Prosthet Dent 1981;46(4):450-53.

20. Pensler A V. Photography in the dental practice (II). Q uintessence Int Dent Dig 1983;14(8):855-58.

21. Hassel $A J$, Koke U, Schmitter M, Beck J, Rammelsberg P. Clinical effect of different shade guide systems on the tooth shades of ceramic-veneered restorations. Int J Prosthodont 2005; 18(5):422-26.

22. Corciolani G, Vichi A, Goracci C, Ferrari M. Colour correspondence of a ceramic system in two different shade guides. J Dent 2009;37(2):98-101.

23. Hassel AJ, Koke U, Schmitter M, Beck J, Rammelsberg P. Clinical effect of different shade guide systems on the tooth shades of ceramic-veneered restorations. Int J Prosthodont 2005; 18(5):422-26.

24. Derbabian K, M arzola R, Donovan TE, Arcidiacono A. The science of communicating the art of esthetic dentistry. Part III: precise shade communication. J Esthet Restor Dent 2001;13(3):154-62.

25. Gokce HS, Piskin B, Ceyhan D, Gokce SM, A risan V. Shade matching performance of normal and color vision-deficient dental professionals with standard daylight and tungsten illuminants. J Prosthet Dent 2010;103(3):139-47.

26. Paramei GV, Bimler DL, Cavonius CR. Effect of luminance on color perception of protanopes. V ision Res 1998;38(21):3397-401.

27. M cA ndrew R, Chan PW, M ilward PJ . A $n$ assessment of shade taking by dental undergraduates. Eur J Prosthodont Restor D ent 2010;18(1):13-16.

\section{ABOUT THE AUTHORS}

\section{Mohammadreza Nakhaei (Corresponding Author)}

A ssistant Professor, Department of Prosthodontics, Faculty of Dentistry and Dental Research Center, M ashhad University of M edical Sciences, V akilabad BIvd, M ashhad, Iran, PO B ox: 91735984, Phone: +98-511-8829501, Fax: +98-511-8829500, e-mail: mrn_nakhaei@yahoo.com

\section{Jalil Ghanbarzadeh}

A ssociate Professor, Department of Prosthodontics, Faculty of Dentistry and Dental R esearch C enter, M ashhad U niversity of M edical Sciences, M ashhad, Iran

\section{Shirin Keyvanloo}

General Dentist, M ashhad, I ran

\section{Samin Alavi}

Postgraduate Student, Department of R estorative Dentistry, K erman University of M edical Sciences, Kerman, I ran

\section{Hamid Jafarzadeh}

A ssociate Professor, D epartment of Endodontics, F aculty of D entistry and Dental R esearch Center, $M$ ashhad U niversity of M edical Sciences Mashhad, I ran 